Portland State University

PDXScholar

12-6-1996

\title{
Chemical Communication in House Mice (Mus musculus): Can They Recognize Gender from the Anogenital, Harderian Gland or Mouth/Nose Odor?
}

Dawn Michele Andrews

Portland State University

Follow this and additional works at: https://pdxscholar.library.pdx.edu/open_access_etds

Part of the Biology Commons, and the Other Animal Sciences Commons Let us know how access to this document benefits you.

\section{Recommended Citation}

Andrews, Dawn Michele, "Chemical Communication in House Mice (Mus musculus): Can They Recognize Gender from the Anogenital, Harderian Gland or Mouth/Nose Odor?" (1996). Dissertations and Theses. Paper 5230.

https://doi.org/10.15760/etd.7102

This Thesis is brought to you for free and open access. It has been accepted for inclusion in Dissertations and Theses by an authorized administrator of PDXScholar. Please contact us if we can make this document more accessible: pdxscholar@pdx.edu. 


\section{THESIS APPROVAL}

The abstract and thesis of Dawn Michele Andrews for the Master of Science in Biology were presented December 6, 1996, and accepted by the thesis committee and department.

COMMITTEE APPROVALS:

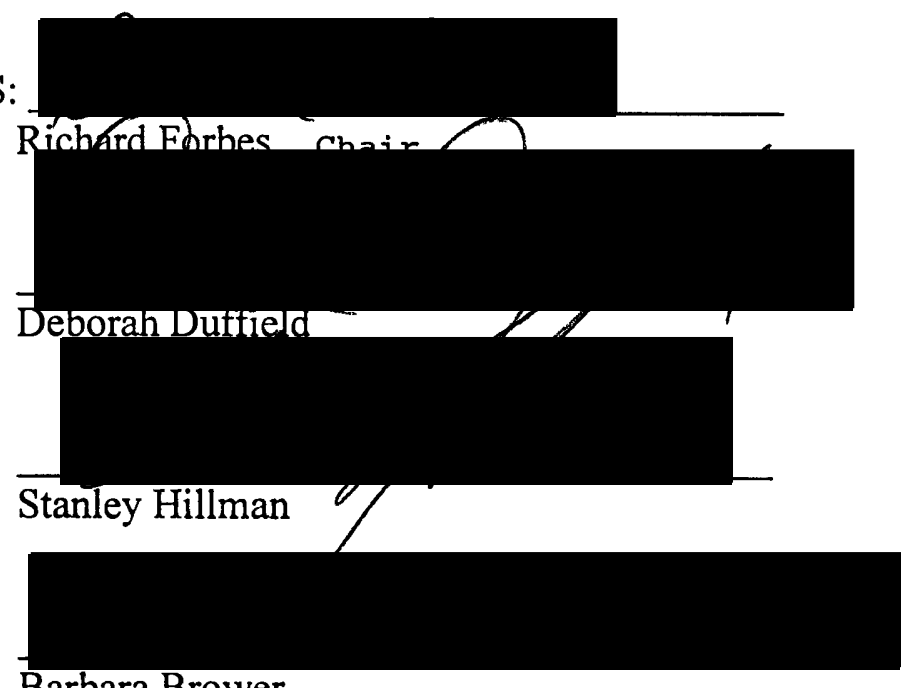

Barbara Brower

Representative of the Office of Graduate Studies

DEPARTMENT APPROVAL:

Leonard Simpson, Chair

Department of Biology

ACCEPTED FOR PORTLAND STATE UNIVERSITY BY THE LIBRARY

by

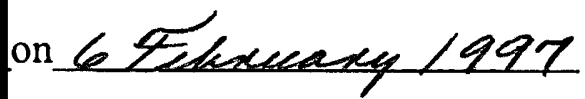




\begin{abstract}
An abstract of the thesis of Dawn Michele Andrews for the Master of Science in Biology presented December 6, 1996.
\end{abstract}

Title: Chemical Communication in House Mice (Mus musculus): Can They Recognize Gender from the Anogenital, Harderian Gland or Mouth/ Nose Odor?

Identifying the sensory systems animals employ to communicate chemically and the function of the chemical signals facilitates further understanding of chemical communication. Increased knowledge of how animals use the olfactory and vomeronasal systems in order to interpret the meaning of body odors will aid in developing a more detailed organization of chemosensory pathways. The message that each body odor contains can change from species to species.

The purpose of this thesis was to study three previously untested body odors in house mice (M. musculus) for their role in gender recognition of conspecifics. These odors are the anogenital (feces, urine, and preputial gland secretions), the Harderian gland (Harderian gland sebaceous secretion; gland located at inner corner of eye), and mouth/nose (saliva, mucus, and food). The amount of time in seconds and the number of sniffs were measured in an habituation paradigm which involved four trials per odor. 
The means of the amount of time spent sniffing and the number of sniffs per odor showed that the mice sniffed the novel odor the most, the non-novel an intermediate amount, and the control the least amount. The mice recognized the novel as foreign and the non-novel as familiar and the mice could not determine the gender of the odor-donor from any of the three odors. 
CHEMICAL COMMUNICATION IN HOUSE MICE (Mus musculus):

CAN THEY RECOGNIZE GENDER FROM THE ANOGENITAL,

HARDERIAN GLAND OR MOUTH/NOSE ODOR?

by

DAWN MICHELE ANDREWS

A thesis submitted in partial fulfillment of the

requirements for the degree of

MASTER OF SCIENCE

in

BIOLOGY

Portland State University

1997 


\section{ACKNOWLEDGEMENTS}

This thesis is dedicated to those special vertebrates called mammals because they are an endless source of amazement for me. I would like to thank all my family and friends for their patience and encouragement (especially Mom, Dad, Kris, Lance, and Travis). I would also like to thank Dr. Forbes, Dr. Duffield, and Dr. Hillman. 
TABLE OF CONTENTS

\section{PAGE}

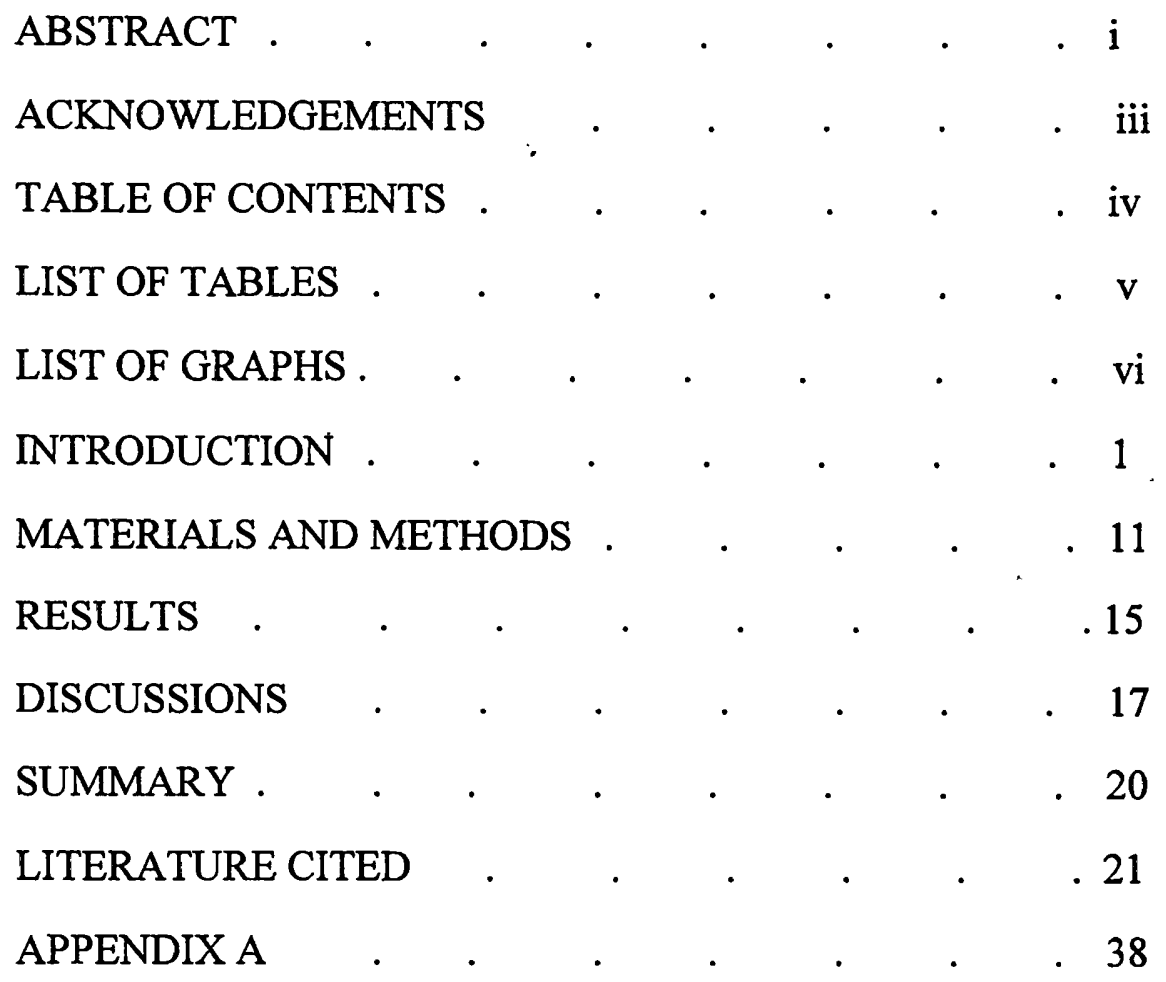




\section{LIST OF TABLES}

\begin{tabular}{|c|c|c|c|c|c|}
\hline $\mathrm{TAB}$ & & & & & PAGE \\
\hline I & $\cdot$ &. & . & . & 27 \\
\hline II a & . & . & . & . & 28 \\
\hline II b & . & . & . & . & 28 \\
\hline III & . & . & . & . & 29 \\
\hline IV & • & . & . & . & 30 \\
\hline V & . & . & . & . & 32 \\
\hline
\end{tabular}


vi

LIST OF GRAPHS

GRAPH

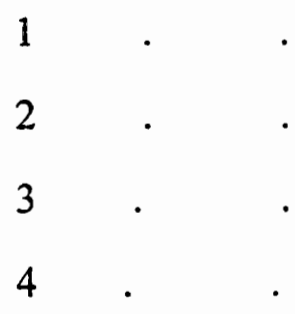

PAGE

34

35

36

37 


\section{INTRODUCTION}

Olfaction, or smelling, is one of many senses animals use in order to gather information about the environment in which they live. Olfaction involves the olfactory mucosa and/or the vomeronasal (or Jacobson's) organ located in the rostrum (Ladewig and Hart, 1980; Wysocki, 1979, 1980, and 1989; Johnston, 1985; and Schaal et al., 1995). The process of olfaction involves the detection of chemical compounds, or stimuli, through a medium of water or air; the integration of chemical stimuli; and the response. Animals detect chemical stimuli by maneuvering through a gradient in a medium such as water (hydrotaxis) or air (anemotaxis) (Agosta, 1992). The integration of stimuli occurs in the accessory olfactory bulb and cerebral cortex. Animals respond to two types of olfactory chemical stimuli: pheromones and other body odors. Pheromones are described as "chemical substances which when released into an animal's surroundings, influence the behavior or development of other individuals of the same species" (Abercrombie et al., 1992). When the stimulus detected is a pheromone, two types of responses are possible. The response may either be a physiological change, in the case of a primer pheromone, or it may be a behavioral change, in the case of a releaser pheromone. Animals can detect body odors which also provide information to the receiver. These odors are present in urine, feces, glandular secretions, and in the degradation of bodily odors or metabolic byproducts by bacteria (see 
Brown and MacDonald, 1985; Lane-Petter, 1967; Meredith, 1983; Strauss and Ebling, 1970; Tinbergen, 1952; and Whitten, 1983). The detection and identification of the body odors has many functions in intraspecific chemical communication. These include mating and mate selection, acceleration or suppression of reproductive maturation, individual, and gender recognition, rearing of young, establishment and maintenance or territories (Weinhold and Ingersoll, 1988), search for nourishment, escape from predators, and status in a social hierarchy. The function of pheromones and body odors varies among the species, but their ultimate function is to aid the animal in individual, gender, and species recognition.

Chemical communication has many functions in animals, particularly in vertebrates. For example, in house mice (Mus musculus) an aggressioneliciting odor present in the urine of males aids in the identification of foreign males (Ropartz, 1966; Archer, 1969; and MacKintosh and Grant, 1966). Ropartz (1968) studied aggression and its pathways in the olfactory bulb of house mice regarding what information mice receive from the aggressioneliciting odor in urine. Perhaps the mice recognize gender, familiarity of the individual, or dominance or subordinance of an individual from the aggressioneliciting odor. No research has yet been done to determine if house mice can recognize gender from urine or feces. The possibility of individual, gender or species recognition from odors present in house mouse urine or feces could supply needed information about the function of this species' odors in chemical communication. Another possible source of odor contributing to gender recognition may be the preputial glands, which may play a role such as scent marking, in male territoriality (McKinney and Christian, 1970; Mugford and 
Nowell, 1971b; Crowcroft, 1966; MacKintosh, 1970; and Anderson and Hill, 1965). In contrast to males, female house mice possess an anti-aggression pheromone (Mugford and Nowell, 1971a). How the preputial glands (or clitoral glands as they are called in females) function in the production of the anti-aggression pheromone is, again, unknown. The production of the pheromone is dependent on the ovaries. Studying the response of house mice to the anogenital odor from both genders may provide information as to whether mice can recognize gender from this particular odor. An anogenital odor would contain urinary, fecal, and preputial gland odors. If house mice can determine gender from the anogenital odor, then it is possible that they may be able to recognize gender from other odors as well. The current literature on gender recognition for house mice led to the following question: Can house mice recognize the gender of an individual just by its odor, for example, the anogenital odor? Or, can mice recognize gender from another odor like the Harderian gland (an infrequently-studied specialized gland located in the inner corner of the eye that lubricates the eyelid), or from the mouth/nose region? Another possibility is that house mice use a combination of odors in order to recognize gender. The single odor or combination of odors may also enable individual and species recognition.

Determining whether a house mouse can recognize the gender of another mouse from its anogenital, Harderian gland, or mouth/nose odor is relevant to biology because it would show how the odors of a mouse function in intraspecific chemical communication. In the literature on chemical communication, glandular secretions and body odors of animals are used to discriminate between gender, age or status in social hierarchy (Mueller- 
Schwarze, 1974; Mykytowycz, 1974; and Bronson, 1974). Odors have several effects on house mouse reproduction. The first is the Whitten effect where a mouse's estrous cycle is modified (Parkes and Bruce, 1961). The Lee-Boot effect is the increase in pseudopregnancies due to female-female interaction (van der Lee and Boot, 1955 and 1956). Another effect, the Bruce effect, blocks pregnancy in females when exposed to foreign males or their odors (Bruce, 1959).

Many odors have been found to function in gender recognition. Pfeiffer and Johnston (1994) made hamsters anosmic (i.e., unable to smell) by surgically removing the vomeronasal organ and treating the olfactory mucosae to cease their odor-detecting capabilities. The anosmic males showed no response to females or female odors. Consequently, it was demonstrated that the olfactory and vomeronasal systems are involved in odor detection in hamsters. Pfeiffer and Johnston (1992) studied the roles of vaginal secretions, behavioral interactions, and housing conditions in socially stimulated androgen surges in male hamsters. They found that the presence of a vaginal secretion was not necessary as a cue for androgen surges in sexually experienced males. Therefore, there must be another chemical cue in females that induces androgen surges in males, but the authors did not comment on this. The authors also found that the differential response between individuals in sexual performance was not correlated with changes in the androgen levels which, the authors concluded, suggests that androgen or other similar hormonal response are not graded but are all-or-none. Gudermuth et al. (1992) found that female Djungarian hamsters (Phodopus campbelli) exhibited accelerated reproductive development when housed with an adult male instead of a weanling sister or 
alone. Females also showed reproductive suppression when they were housed with a weanling sister. The authors concluded that a chemical cue present in the bedding induced the changes in the reproductive development of female djungarian hamsters. It may be that the male's soiled bedding contained an odor(s) which caused the accelerated development. Conversely, the lack of the odor(s) in sister's bedding may have suppressed the development of the female. Ferkin and Johnston (1993) studied the role of gonadal hormones in the control of sexually attractive components in urine and the anogenital area in meadow voles (Microtus pennsylvanicus). Using normal and glandectomized voles that received hormone therapy, the authors found that the sexually attractive components of urine and the anogenital area did not depend on gonadal hormones alone. Since sexually attractive chemical cues are present in the urine and anogenital area of meadow voles, they may also be present in these location in other rodents as well, as in the house mouse.

Few authors have identified chemical compounds of glandular secretions. Clapperton et al. (1989) bioassayed eight synthetic compounds of the anal gland secretion in ferrets (Mustela furo) in order to identify which compound(s) facilitates individual recognition. The anal gland functions in territoriality and usually is present in territorial carnivores. Ferrets were most attracted to two of the eight compounds (2-propylthietane and trans- and cis2,3-dimethylthietane). Therefore, ferrets recognize conspecifics from two chemical compounds in the anal gland. It is possible that these chemical compounds that facilitate recognition in ferrets, which are carnivores, may also be found in the anal gland secretions of other carnivores. Jorgenson et al. (1978) provided another example of the identification of chemical compounds 
in body odors that facilitate recognition. Wilson et al. (1978) identified a chemical compound in the scent markings of the red fox (Vulpes vulpes). The function of the chemical compound may be territoriality. Jorgenson et al. (1978) studied the chemical constituents in red fox urine during the winter. Winter was chosen for urine collection because that is the red fox's mating season. The compound quinaldine was found only in male urine, but more importantly, many of the constituents found in the red fox's urine were also found in the urine of other species. Therefore, quinaldine functions in gender recognition in red fox, since it is only produced during the mating season of this species. Whitten et al. (1980) induced scent marking in red fox with a synthetic compound. Perhaps other species advertise their reproductive receptiveness in the urine or in another substance, for example, in glandular secretions.

Body odors and pheromones, either present in urine, feces or glandular secretions, function in individual recognition in many species. The Beauchamp et al. (1990) study of house mice revealed that the class I Major Histocompatability Complex (MHC) genes gave an individual mouse its unique odor. Therefore, it can be argued that animals have a unique odor which is detected by conspecifics. Other authors have studied the genetics and population dynamics of house mice (e.g., Anderson, 1964; Blair, 1943; Bronson, 1979; Reimer and Petras, 1967; and van Oortmerssen, 1970). Johnston (1990) and Johnston et al. (1993) studied chemical communication of golden hamsters (Mesocricetus auratus). Johnston et al. (1993) studied individual odors of golden hamsters for evidence of specialization of function. The results showed that males discriminated and recognized individual 
differences in some but not all odors of males. Males identified individuals based on flank and ear gland secretions, but not on saliva or secretions from the feet, behind the ear, back, chest or from the sides of flank-glandectomized males. The authors found that golden hamsters recognized individuals from flank and ear gland secretions. Lai and Johnston (1994) studied various odors from male Djungarian hamsters for individual recognition. The authors used a habituation technique to collect the data which involved the presentation of novel (foreign) and non-novel (familiar) odors and a control. They found that males identified other males by odors from the midventral gland, urine, feces, mouth, and corner of mouth odors. However, odors from the genital region, hindfeet, fur from behind the ears, and fur from the back did not facilitate individual recognition in the hamsters. Johnston and Rasmussen (1984) discovered that male hamsters preferred novel (foreign) females over females with which they were recently sexually sated with (non-novel or familiar). Consequently, the authors found that the chemical cue males used to discriminate between novel and non-novel females was the flank gland. Therefore, the male hamsters recognized individual females by investigating female flank gland odor. Vaginal secretions and the secretions from the head region were also studied, but they were not found to facilitate individual recognition. Further study revealed that the flank gland facilitated but was not necessary for individual recognition. Hence, another odor(s) besides the flank gland allows individual hamsters to recognize each other. Perhaps testing the anogenital, Harderian gland, and mouth/nose odors would provide more information about individual recognition in rodents. 
Rabbits' odors have also been studied for their roles in social chemical communication (Myers and Poole, 1962). Hesterman and Mykytowycz (1982a) studied European rabbits (Oryctolagus cuniculus), which form social groups. The authors found that in all male groups individuals smeared with the inguinal gland secretions of a foreign individual (i.e., not from the group) were attacked, while those smeared with the chin gland secretion, urine or perfume were not attacked. The authors argued that the inguinal gland odor, but not the chin gland, urine or perfume, functions in individual recognition in European rabbits. Hesterman and Mykytowycz (1982b) then studied how the inguinal gland secretion functioned in all-female groups. The authors concluded that the inguinal gland secretion functions in gender identification, status in a social hierarchy, and group (individual) recognition. A study by Mykytowycz et al. (1976) revealed that in the European rabbits chemical cues in feces, urine, inguinal gland, and submandibular gland facilitated individual (group) recognition. The authors argued that animals used odors to gain space requirements for a home range and territory and that the odors an animal can perceive and produce are correlated with the spatial requirements of the animal (i.e., social status in the group). The Mongolian gerbil (Meriones unguiculatus) (Thiessen et al., 1971), the house mouse (Anderson and Hill, 1965; and Crowcroft, 1955), and Norwegian rats (Rattus rattus) (Calhoun, 1961) are also territorial rodents. Johnston and Mueller (1990) determined that scent marking by males in the territorial species the golden hamster is mediated by the olfactory system instead of the vomeronasal system. Johnston (1992) then studied territoriality in female golden hamsters and found that they use the olfactory system to detect scent marks and use both olfactory and vomeronasal 
systems in ultrasonic calling. Yahr (1983) studied scent marking behavior in house mice. Perhaps secretions from other glands such as the preputial glands in other animals help identify gender, individuality, and social status. It is possible that a reproductively receptive female given the choice of an odor from two males (which advertises each male's reproductive and social status) would choose the odor of the male that is reproductively mature and has the higher social status. In European rabbits, this odor comes from the inguinal gland. In hamsters these odors come from the midventral gland, urine, feces, mouth, corner of mouth, flank gland, ear gland, vaginal secretions, and anogenital area.

Besides gender and individual recognition, some odors provide information for interspecific recognition in animals. Johnston and Robinson (1993) tested golden hamster flank gland and Djungarian hamster ventral gland for recognition between the species. Both species identified the other species from the gland secretions. Consequently, the authors argued that golden and Djungarian hamsters recognize the other species by either flank or ventral gland secretions. Here is an example of an odor (flank gland) performing individual and species chemical recognition. Rodents (Mus musculus, Peromyscus maniculatus, and Rattus norvegicus) have also been shown to use chemical cues to recognize different species (Wuensch, 1992). However, the response to interspecific odors was minimal. Zimmerling and Sullivan (1994) studied the effect of weasel semiochemical from the anal gland secretion on deer mice ( $P$. maniculatus). The semiochemical was found to have no reproductive effect on deer mice and, hence, no effect on population dynamics. The authors argued that deer mice have no behavioral responses to weasel 
odors. Other authors have studied the population dynamics of rodent species in response to odors of this weasel. Jedrzejewski and Jedrzewska (1989) discovered that weasel odor caused bank voles (Arvicola) to increase their use of space. In particular, juveniles, nonreproductive adults, and reproductively active male voles changed their use of space the most; i.e., they were displaced the most when exposed to weasel odors. The juveniles and nonreproducing females were the only voles that did not abandon their ranges when exposed to weasel odors.

Many odors have been studied in many animals for their role in gender, individual, and species recognition, much research focusing on which odors hamsters employ to recognize other hamsters of the same species. However, there is a lack of literature on which odors house mice use to recognize gender. The purpose of this study was to test whether house mice could recognize the gender of other house mice from the anogenital, Harderian gland, and mouth/nose odors. 


\section{MATERIALS AND METHODS}

The odors of 23 ( 9 males and 14 females) pet shop variety house mice were used in this study. Each mouse was housed independently in a plastic wiretopped cage with a glass water bottle. Mice were fed ad libitum rat lab chow. Corn cob granules and paper towels were used as bedding. Cages were kept in a temperature controlled room (average temperature 78-80 F). Mice were kept on a $12 \mathrm{hr}$ light:12 hr dark cycle. Data was collected one hour into the dark cycle using red light (60 watt bulb). The odors tested were the anogenital, Harderian gland, and mouth/nose. (For a list and definitions of variables see page 38). The anogenital odor (odor 1) contains urinary, fecal, and preputial gland secretion. The Harderian gland (odor 2) (located in the inner corner of the eye) contains the odor of the secretion. The mouth/nose odor (odor 3) contains saliva and mucus. The three odors were chosen based on the lack of literature on the role of these odors in house mouse gender recognition.

The experimental design used was an habituation paradigm modified after Lai and Johnston (1994). The habituation paradigm, or technique, was used to measure the amount of time a mouse spent sniffing an odor and the number of times the odor was sniffed in order to determine if the mice can recognize gender of a conspecific by its odor alone. The habituation technique was chosen to determine whether a mouse could identify the gender of another by smelling its odor because this technique has been used to determine individual 
recognition. Consequently, it was assumed that the habituation technique can also be used to determine if gender recognition occurs.

Prior to data collection a pair of mice was chosen at random. The pair was of the same sex (male-male or female-female) or the opposite sex (malefemale). Each pair was placed in a 20 gallon terrarium with clean corn cob granules for a 30 minute introductory period. During this period of time the mice smelled each other and became familiar with each other's body odors. Each member of a pair that spent time with the other became the non-novel or familiar odor-donor for the other mouse of the pair. This non-novel odordonor provided the anogenital, Harderian gland, and mouth/nose odors for the other mouse it was housed with during the introductory period. Therefore, each mouse had its own non-novel odor-donor; i.e., no mouse was used as a non-novel odor donor for more than one mouse per odor. Likewise, the novel or foreign odor came from a mouse (at random) that had no previous contact with the mouse being tested. Ultimately, each of the 23 mice had several roles in this experiment. First, each served as the non-novel (familiar) odor-donor, and later each served as the novel (foreign) odor-donor. Finally, each served as the mouse from which data was collected. All odors were collected from the odor-donors and presented to mice for data collection on clean glass stir rods $(23.5 \mathrm{~cm} \times 0.5 \mathrm{~cm})$. Non-novel and novel odors were collected by rubbing a clean glass stir rod 10 times against the appropriate area on the mouse. The control was a clean glass stir rod. Glass stir rods were cleaned with warm tapwater and mild detergent. Rubber gloves were worn by the experimenter to minimize human odors on the glass stir rods. In order to test for gender recognition, the non-novel odor was the same or opposite the sex of the mouse 
from which data was collected (nnsx $=1$ or 0 , respectively). The novel was also the same or opposite the sex of the mouse from which data was collected (nvsx $=1$ or 0 , respectively). Differences in the amount of time of the number of sniffs between these variables (nnsx and nvsx) should indicate whether house mice can recognize gender from these odors.

Using the habituation technique, data collection involved four consecutive trials (tr) per odor. Each mouse was tested for its response to all three odors. Each trial lasted 15 minutes in duration with 5 minutes between trials. Regardless of the trial (1-4), the non-novel, novel, and control were always presented on freshly-cleaned glass stir rods with the odor freshly taken from the odor-donor. Two glass stir rods were presented to a mouse in its own cage in all trials (1-4) for each odor. The glass stir rods were lowered through the top of the cage until they were about $2 \mathrm{~cm}$ from the corn cob granules at the bottom of the cage. The glass stir rods were held in place with a Styrofoam platform. The odors presented in trials 1-3 were the non-novel (familiar) and control. The odors in trial 4 were the non-novel and novel (foreign). The control was omitted in the fourth trial because this trial was for the comparison of non-novel and novel. During all trials (1-4) data was collected on the mouse doing the sniffing. Sniffing was defined as actively licking, biting, and obvious smelling within $1 \mathrm{~cm}$ of the glass stir rod for 2 seconds before recording began. The data collected was the amount of time spent sniffing an odor which was measured to the one-hundredth of a second using a stopwatch and the time was rounded off to an even decimal point. The amount of time was collected for the non-novel (tnn), control (tcn), and novel (tnv). Data were 
also collected on the number of sniffs for each trial and odor. Again, nonnovel (ns1), control (ns2), and novel (ns3) were measured.

I expected the amount of time spent sniffing the non-novel (tnn) and control (tcn) in trials $1-3$ to decrease because the mouse was habituating to the nonnovel (familiar) odor. However, in trial 4 the amount of time spent sniffing should be much greater than in trials 1-3 because the mouse should respond more to the novel (foreign) odor. When the sex of the novel was opposite the sex of the mouse (nvsx-0) doing the sniffing (ms), the response should be more than when the sex of the novel is the same (nvsx=1) as the sex of the mouse (ms). I hoped my data would thus enable me to discern some correlation between non-novel (familiar) and novel (foreign) anogenital, Harderian gland, and mouth/nose odors in gender recognition in house mice.

Time (tnn, tcn, and tnv) and number of sniffs (ns1, ns2, and ns3) were analyzed using various statistical tests. The level of statistical significance was assigned at $95 \%$. The Chi-square test was used to test if the difference in the amount of time spent sniffing the non-novel (tnn) and novel (tnv) was significant and how well their distributions responses fit a distribution. The Friedman two-way analysis by rank (non-parametric) was used to test if several matched pairs samples were from the same distribution (assigned at the $95 \%$ level of significance and was two-tailed). The two-sample t-test (with Levene's test for equality of variances) was used to test whether the difference in the means of non-novel and novel was significant.

Variables in this study, their definitions, and their abbreviations are summarized in Appendix A (pg.38). 


\section{RESULTS}

The results of the statistical tests (Chi-square, Friedman two-way analysis of variance by rank, t-test, and multiple regression) revealed significance in the amount of time spent sniffing and the number of sniffs. Table V (pg.32) shows the statistical tests used to evaluate differences between variables and indicates the level of significance. The Chi-square test indicated that the difference in the time spent sniffing the novel (tnv) and the odors 1,2 , and 3 was significant with a $\mathrm{X}^{2}=19.4, \mathrm{p}=.0001$. Table I (pg.27) shows the descriptive statistics of Chi-square test. The difference between the time spent sniffing the novel (tnv) versus the habituated non-novel and the number of times the novel was sniffed (ns3) was significant when the sex of the novel was the same or the opposite the sex of the mouse (nvsx=1 and nvsx=0). The time spent sniffing the nonnovel (tnn) compared to the control and the odors (1-3) was significant. The amount of time spent sniffing the non-novel (tnn) compared to the control and whether the sex of the non-novel was the same or the opposite the sex of the mouse ( $\mathrm{nnsx}=1$ and $\mathrm{nnsx}=0$, respectively) was also significant. The difference in the number of sniffs for the non-novel (ns1) compared to the control (ns2) was significant. The difference in the number of sniffs for the non-novel compared to the control was significant for the odors $(1-3)$. The difference in the number of sniffs for the non-novel (ns1) compared to the control for the trials (1-4) and odors (1-3) was significant. The difference in the number of sniffs of the non-novel (ns1) compared to the control (ns2) and the sex of the 
mouse (sex) was significant. The difference in the number of sniffs of the nonnovel (ns1) compared to the novel (ns3) for the odors (1-3) was significant. The number of sniffs of the control (ns2) compared to the non-novel for the odors $(1 \& 2)$ was significant. The number of sniffs of the control compared to the habituated non-novel for the trials (1-4) and odors (1-3) was significant. The difference in the number of sniffs of the control (ns2) compared to the non-novel and the time spent sniffing the control (tcn) was significant for odor 1 and 3. 


\section{DISCUSSION}

The majority of mice responded to the anogenital, Harderian gland, and mouth/nose odors when presented with them. They seemed to respond both to the non-novel odor as familiar and the novel as foreign, as well as to the control which was the absence of odor. The sums of the times and the number of sniffs (see Table IIa and IIb, pg. 28) showed that for all three odors, except for the number of sniffs for odor 3 , the relationship was $\operatorname{tnv}>\operatorname{tnn}>\operatorname{ten}$ and ns $3>n s 1>n s 2$. The relationship of the novel, non-novel, and control is in agreement with the assumption that mice habituated to a non-novel odor respond more when presented with a novel that a non-novel odor. This habituation technique agrees with Lai and Johnston (1994) methods. Therefore, the experimental design did habituate the house mice to a non-novel odor.

In order to evaluate whether gender recognition occurred, results for the statistical significance need to be discussed. The Chi-square test found the response to the tnv and odor 1,2 , and 3 were significantly different from the habituated non-novel response (Table V, pg.32). Table I (pg. 27) and graphs 14 (pp. 34-37) show the relationship of the means of the times and number of sniffs: $\operatorname{tnv}>\operatorname{tnn}>\operatorname{tcn}$ and $n s 3>n s 1>n s 2$. Therefore, there appeared to be a pattern to the amount of time a mouse sniffs a novel anogenital, Harderian gland, and mouth/nose odor. The Friedman two-way analysis by rank test showed that the difference in the number of sniffs for the non-novel and novel 
and the odors 1,2 , and 3 was statistically significant. This demonstrates that the mice responded more to the novel than the non-novel odor. The twosample t-tests revealed a significant difference between the time and number of sniffs of the novel and when the novel sex was the same $(p=.027)$ sex of the mouse doing the sniffing. The two-sample t-test revealed a significant difference between the time and number of sniffs of the novel and when the novel sex was the and opposite (.035) sex of the mouse doing the sniffing (see Table IV, pg.30). The analysis of the t-test means of odors 1,2, and 3 (Table III, pg.29) revealed that the mice sniffed the novel odor (regardless of the odor) the most number of sniffs, the non-novel and intermediate number of sniffs, and the control the least number of sniffs. For odors 1,2, and 3 the mean values for the number of sniffs for novel, non-novel, and control were all ns3 $>$ ns $1>$ ns2. Based on the means of the number of sniffs, the odors are also rated as odor $1>$ odor $2>$ odor 3 . Therefore, the mice spent the most number of sniffs investigating the anogenital odor, the Harderian gland an intermediate number of sniffs, and the control the least. The means of all odors for the amount of time the novel, non-novel, and control were sniffed showed a trend similar to that for the number of sniffs $(\operatorname{tnv}>\operatorname{tnn}>\operatorname{tcn})$. In contrast to the number of sniffs, the relationship between the amount of time spent sniffing the odors was odor $2>$ odor $1>$ odor 3 . Therefore, the mice spent the most amount of time sniffing the Harderian gland the most, the anogenital an intermediate amount, and the mouth/nose the least.

While individual recognition based on odors has been demonstrated in many species, including house mice, gender recognition literature is limited. My data show that the habituation paradigm experimental procedure was more 
useful for detecting novel response in house mice, than for distinguishing gender. The amount of time and the number of times all of the odors were sniffed was significant when the sex of the novel was from a mouse of the opposite or of the same sex. Mice spent the most amount of time sniffing the anogenital odor, but sniffed the Harderian gland odor the most number of times. It is not possible to determine whether the mice responded to the odor because it was novel or because they were recognizing gender. With respect to the mouth/nose and anogenital odors, some unavoidable circumstances may have influenced the responses of the mice; such as, volatile compounds in the odors may have made them persist longer on the glass stir rods, food particles may have persisted in the mouth/nose odor, fecal, urinary, and preputial gland secretion are components of the anogenital odor, and grooming could have distributed anogenital odor to the mouth/nose odor.

In this study, I was able to show house mice exhibit differences in response to different sources of odors. However, the complexity of odor response is such that to differentiate between motivation for the response, i.e. gender of novel, isolation of each odor component, and the specific response to that component, will need to be tested in another way. 


\section{CONCLUSION}

Mice respond more to novel odors than to non-novel and control odors. Differences in the amount of time and number of sniffs of the novel and nonnovel were significant when compared to the sex of the non-novel and novel and the sex of the mouse. Mice responded more to the novel than the nonnovel or control. Mice sniffed the novel Harderian gland odor the most, the anogenital an intermediate amount, and the mouth/nose odor the least. The mice sniffed the anogenital odor the greater number of times and the mouth/nose the least. The amount of time and number of sniffs of the novel odor was statistically significant from the non-novel and control odors but, both the same sex and opposite sex trials gave a similar "Novel" response. The null hypothesis that mice will respond to the novel odors of the opposite and same sex was rejected. It was not possible to determine whether the house mice recognized gender from the anogenital, Harderian gland, and mouth/nose odors. However, gender recognition of the three odors may occur, but the habituation technique used may have recorded the response to the novel, and not the gender. Factors, such as aggression-eliciting pheromones or estrous cycle, which could not be controlled in these experiments could have contributed to masking a difference in response between the same and opposite sex. 


\section{LITERATURE CITED}

Abercrombie, M., Hickman, M., Johnson, M.L., and Thain, M. The Penguin

Dictionary of Biology, 8th edition. Penguin Group: London. 1992.

Agosta, W.C. Chemical Communication: The Language of Pheromones.

New York: Scientific American Library; 1992.

Anderson, P.K. (1964). Lethal Alleles in Mus musculus: Local Distribution and the Evidence for the Isolation of Demes. Science, N.Y., 145: 177178.

Anderson, P.K. and J.L. Hill. (1965). Mus musculus: Experimental Induction of Territory Formation. Science, 148:1753-1755.

Archer, J. (1968). The effect of Strange Male Odor on Aggressive Behavior in Male Mice. I. Mamm., 49(3): 572-575.

Beauchamp, G.K., Yamazaki, K., Duncan, H., Bard, J., and Boyse, E.A. Genetic Determination of Individual Mouse Odour. In:

Chemical Signals in Vertebrates V. MacDonald, D.W., Mueller-

Schwarze, D. and Natynczuk, S., eds. New York: Oxford

Science Publications; 1990. (pp.244-254).

Blair, W.F. (1943). Population Dynamics of Rodents and Other Mammals. Advan. Genet., 5: 1-41.

Bowers, J.M. and B.K. Alesander. (1967). Mice: Individual Recognition by Olfactory Cues. Science, 158: 1208-1210.

Bronson, F.H. Pheromonal Influences on Reproductive Activities in Rodents.

In: Neuberger, A. and Tatum, E.L., eds. Pheromones. Amsterdam:

North-Holland Research Monographs. Frontiers in Biology, Vol.32;

1974. (pp.344-365).

Bronson, F.H. (1979). The Reproductive Ecology of the House Mouse. Q.

Rev. Biol., 54: 265-299.

Brown, R.E. and MacDonald, D.W., eds. Social Odours in Mammals, Vol. I. Oxford Science Publications; 1985. (pp.364-457).

Bruce, H.M. (1959). An Exteroceptive Block to Pregnancy in the Mouse. Nature, Lond., 184: 105. 
Calhoun, J.B. (1961). Determinants of Social Organization Exemplified in a Single Population of Domesticated Rats. New York Acad. Sci., 23: 437-442.

Clapperton, B.K., Minot, E.O., and Crump, D.R. (1989). Scent Lures from Anal Sac Secretions of the Ferret (Mustela furo L.). I. Chem. Ecol., 12 (1): 291-308.

Crowcroft, P. (1955). Territoriality in Wild House Mice. I. Mamm., 36: 299301.

Crowcroft, P. (1966). Mice All Over. London: Foulis.

Ferkin, M.H. and Johnston, R.E. (1993). Roles of Gonadal Hormones in Control of Five Sexually Attractive Odors of Meadow Voles (Microtus pennsylvanicus). Hormones and Behavior, 27: 523-538.

Gudermuth, D.F., Butler, W.R., and Johnston, R.E. (1992). Social Influences on Reproductive Development and Fertility in Female Djungarian Hamsters (Phodopus campbelli). Hormones and Behavior, 26: 308329.

Hesterman, E.R. and Mykytowycz, R. (1982a). Misidentification by Wild Rabbits, Oryctolagus cuniculus, of Group Members Carrying the Odor of Foreign Inguinal Gland Secretion, I. Experiments with All-Male Groups. J. Chem. Ecol., 8(2): 419-427.

Hesterman, E.R. and Mykytowycz, R. (1982b). Misidentification by Wild Rabbits, Oryctolagus cuniculus, of Group Members carrying the Odor of Foreign Inguinal Gland Secretion, II. I. Chem. Ecol., 8(4): 723-729.

Jedrzejewski, W. and Jedrzewska, B. (1989). Effect of a Predator's Visit on the Spatial Distribution of Bank Voles: Experiments with Weasels. Can. J. Zool., 68: 660-666.

Johnston, R.E. Olfactory and Vomeronasal Mechanisms of Communication. In: Pfaff, D.W., ed. Taste, Olfaction, and the Central Nervous System. New York: Rockefeller University Press; 1985.

Johnston, R.E. Chemical Communication in Golden Hamsters: From Behavior to Molecules and Neural Mechanisms. In: Dewsbury, D.A., ed., Contemporary Issues in Comparative Psychology, 381-409; 1990. 
Johnston, R.E. (1992). Vomeronasal and/or Olfactory Mediation of Ultrasonic Calling and Scent Marking by Female Golden Hamster. Physiol. and Behav., 51: 437-448.

Johnston, R.E. and Mueller, U.G. (1990). Olfactory but not Vomeronasal Mediation Scent Marking by Male Golden Hamsters. Physiol. and Behav., 48: 701-706.

Johnston, R.E., Derzie, A., Chiáng, G., Jernigan, P., and Lee, H. (1993). Individual Scent Signatures in Golden Hamsters: Evidence for Specialization of Function. Anim. Behav., 45: 1061-1070.

Johnston, R.E. and Rasmussen, K. (1984). Individual Recognition of Female Hamsters by Males: Roles of Chemical Cues and of the Olfactory and Vomeronasal Systems. Physiol. Behav., 33: 95-104.

Johnston, R.E. and Robinson, T.A. (1993). Cross-species Discrimination of Individual Odors by Hamsters. Ethology, 94: 317-325.

Jorgenson, J., Novotny, M., Carmack, M., and Copland, G.B. (1978). Chemical Scent Constituents in the Urine of the Red Fox (Vulpes vulpes L.) During the Winter Season. Science, 199: 796-798.

Ladewig, J. and Hart, B.L. (1980). Flehmen and Vomeronasal Organ Function in Male Goats. Physiol. Behav., 24:1067-1071.

Lai, S. and Johnston, R.E. (1994). Individual Odors in Djungarian Hamsters (Phodopus campbelli). Ethology, 96: 117-126.

Lane-Petter, W. (1967). Odour in Mice. Nature, Lond., 216:794.

MacKintosh, J.H. and Grant, E.C. (1966). The Effect of Olfactory Stimuli on the Agnostic Behavior of Laboratory Mice. Z. Tierpsychol., 23: 584-587.

MacKintosh, J.H. (1970). Territory Formation by Laboratory Mice. Anim. Behav., 18: 177-183.

McKinney, E.D. and Christian, J.J. (1970). Effect of Preputialectomy on Fighting Behavior in Mice. Proc. Soc. Exp. Biol. Med., 143: 291-293.

Meredith, M. Sensory Physiology of Pheromone Communication. In: Vandenburgh, J., ed. Pheromones and Reproduction in Mammals. 
New York: Academic Press; 1983.

Mugford, R.A. and Nowell, N.W. (1971a). Endocrine Control Over Production and Activity of the Anti-Aggression Pheromone from Female Mice. I. Endocr., 49: 225-232.

Mugford, R.A. and Nowell, N.W. (1971b). The Preputial Glands as a Source of Aggression-Promoting Odors in Mice. Physiol. and Behav., 6: 247-249.

Mueller-Schwarze, D. Olfactory Recognition of Species, Groups, Individuals and Physiological States Among Mammals. In: Neuberger, A. and Tatum. E.L., eds. Pheromones. By: Birch, M.C. Amsterdam: North-Holland Research Monographs. Frontiers in Biology, Vol.32; 1974. (pp. 316-326).

Myers,K. and Poole, W.E. (1962). A Study of the Biology of the Wild Rabbit, Oryctolagus cuniculus (L.) in Confined Populations. III. Reproduction. Aust. I. Zool., 10: 225-267.

Mykytowycz, R. (1974). Odor in the Spacing Behavior of Mammals. In: Neuberger, A. and Tatum, E.L., eds. Pheromones. By: Birch, M.C. Amsterdam: North-Holland Research Monographs. Frontiers in Biology, Vol.32; 1974. (pp.317-343).

Mykytowycz, R., Hersterman, E.R, and Dudzinski, M.L. (1976). A Comparison of Effectiveness of the Odors of Rabbits, Oryctolagus cuniculus, in Enhancing Territorial Confidence. I. Chem. Ecol., 2: 13-24.

Parkes, A.S. and H.M. Bruce. (1961). Olfactory Stimuli in Mammalian Reproduction: Odor Excites Neurohumoral Responses Affecting Oestrous, Pseudopregnancy, and Pregnancy in the Mouse. Science, 134: 1049-1054.

Pfeiffer, C.A. and Johnston, R.E. (1992). Socially Stimulated Androgen Surges in Male Hamsters: The Roles of Vaginal Secretions, Behavioral Interactions, and Housing Conditions. Horm. and Behav., 26: 283-293.

Pfeiffer, C.A. and Johnston, R.E. (1994). Hormones and Behavioral Responses of Male Hamsters to Females and Female Odors: Roles of Olfaction, the Vomeronasal System, and Sexual Experience. Physiol. and Behav., 55: 129-138. 
Reimer, J.D. and Petras, M.L. (1967). Breeding Structure of the House Mouse, Mus musculus, in a Population Cage. J. Mamm., 48(1): 88-99.

Ropartz, P. (1966). Mise en enivedence d'une odeur de groups chez le souris parla mesure de l'activite locomotrice. C.R. Acad. Sci., Paris, ser. D, 262: 507-510.

Ropartz, P. (1968). The Relation Between Olfactory Stimulation and Aggressive Behavior in Miće. Anim. Behav., 16: 97-100.

Schaal, B., Orgeur, P., and Arnould, C. (1995). Olfactory Preferences in Newborn Lambs: Possible Influence of Prenatal Experience. Behaviour, 132(5-6): 351-365.

Strauss, J.S. and Ebling, F.J. Control and Function of Skin Glands in Mammals. In: Hormones and the Environment: Memoirs of the Society for Endorcrinology, edited by Benson, G.K. and Phillips, J.G., Vol. 18. Cambridge University Press; 1970. (pp.341-371).

Thiessen, D.D., Owen, K., and Lindzey, G. (1971). Mechanisms of territorial Marking in the Male and Female Mongolian Gerbil (Meriones unguiculatus). J. Comp. Physiol. Psychol., 77: 38-47.

Tinbergen, N. (1952). Derived Activities: Their Causation, Biological Significance, Origin and Emancipation During Evolution. Q. Rev. Biol., 27: 1-32.

Van der Lee, S. and Boot, L.M. (1955). Spontaneous Pseudopregnancy in Mice. ACTA Physiol. Pharmac. Neerl., 4: 422-423.

Van der Lee, S. and Boot, L.M. (1956). Spontaneous Pseudopregnancy in Mice, II. ACTA Physiol. Pharmac. Neerl., 5: 213-214.

Van Ortmerssen, G.A. (1970). Biological Significance, Genetics and Evolutionary Origin of Variability in Behavior Within and Between Inbred Strains of Mice (Mus musculus): A Behaviour Genetic Study. Behavior, 38: 1-91.

Weinhold, L.L. and Ingersoll, D.W. (1988). Modulation of Male Mouse Genital Sniff, Attack, and Mount Behaviors by Urogenital Substances from Estrous Females. Behav. Biol., 50: 207-228.

Whitten, W.K. Pheromones and Mammalian Reproduction. In: 
Pheromones and Reproduction in Mammals. Vandenburgh, J.G., ed. Academic Press; 1983. (pp.155-177).

Whitten, W.K., Wilson, S.R., Jorgenson, J.W., Novotny, M., and Carmack, M. (1980). Induction of Marking Behavior in Wild Red Foxes (Vulpes vulpes L.) by Synthetic Urinary Constituents. I. Chem. Ecol, 6(1): 49-55.

Wilson, S.R., Carmack, M., Novotny, M., Jorgenson, J.W., and Whitten, W. K. (1978). Delta3-Isopentýl Methyl Sulfide: A New Terpenoid in the Scent Mark of the Red Fox (Vulpes vulpes). I. Organ. Chem., 43(24): 4675-4676.

Wuensch, K.L. (1992). Fostering House Mice onto Rats and Deer Mice: Effects on Response to Species Odors. Anim. Learn. and Behav., 20(3): 253-258.

Wysocki, C.J. (1979). Neurobehavioral Evidence for the Involvement of the Vomeronasal System in Mammalian Reproduction. Neurosens. Biobehav. Rev., 3: 301-341.

Wysocki, C.J., Wellington, J.L., and Beauchamp, G.K. (1980). Access of Urine Non-Volatiles to the Mammalian Vomeronasal Organ. Science, 26: 781-783.

Yahr, P. Hormonal Influences on Territorial Marking Behavior. In: Svare, B.B., ed., Hormonal and Aggressive Behavior. Plenum, New York; 1983. (pp.145-175).

Zimmerling, L. and Sullivan, T.P. (1994). Influence of Mustelid Semiochemical on Population Dynamics of the Deer Mouse (Peromyscus maniculatus). I. Chem. Ecol., 20(3): 667-689. 
Table I

Descriptive Statistics of the Chi-squared tests on the Independent Variables:

$\begin{array}{lllll}\text { Variable } & \text { Mean } & \text { SD } & \text { Minimum } & \text { Maximum } \\ \text { ns1 } & 2.7 & 3.1 & 0 & 29 \\ \text { ns2 } & 2.1 & 2.0 & 0 & 10 \\ \text { ns3 } & 3.9 & 3.7 & 0 & 25 \\ \text { tnn } & 14.2 & 23.2 & 0 & 258 \\ \text { tcn } & 10.7 & 13.3 & 0 & 73.8 \\ \text { tnv } & 27.3 & 41.5 & 0 & 283.6\end{array}$


Table II a

Sums of times spent sniffing per trial per odor:

$\begin{array}{llll}\text { odor } & \text { tnn } & \text { tcn } & \text { tnv } \\ 1 & 445.2 & 349.9 & 575.0 \\ 2 & 337.4 & 204.7 & 836.8 \\ 3 & 202.4 & 193.5 & 472.4 \\ \text { sum } & 985.0 & 748.1 & 1884.2\end{array}$

Table II b

Sums of number of sniffs per trial per odor:

$\begin{array}{llll}\text { odor } & \text { ns1 } & \text { ns2 } & \text { ns3 } \\ 1 & 67.8 & 66.7 & 94 \\ 2 & 61.8 & 44.0 & 92 \\ 3 & 34.3 & 38.3 & 86 \\ \text { sum } & 163.9 & 149 & 272\end{array}$


Table III

Descriptive Statistics of t-tests on Independent Variable for Odors 1, 2, and 3:

\begin{tabular}{|c|c|c|c|c|}
\hline Variable & Odor & Mean & $\mathrm{SD}$ & SE of Mean \\
\hline ns1 & 1 & 3.5 & 4.2 & .44 \\
\hline$"$ & 2 & 2.6 & 2.7 & .28 \\
\hline$"$ & 3 & 2.1 & 1.8 & .19 \\
\hline $\mathrm{ns} 2$ & 1 & 2.9 & 2.4 & .28 \\
\hline$"$ & 2 & 1.9 & 1.9 & .23 \\
\hline 1 & 3 & 1.6 & 1.5 & .18 \\
\hline $\mathrm{ns} 3$ & 1 & 4.1 & 2.6 & .53 \\
\hline " & 2 & 4.0 & 5.5 & 1.14 \\
\hline$"$ & 3 & 3.7 & 2.3 & .49 \\
\hline $\operatorname{tnn}$ & 1 & 19.4 & 31.9 & 3.33 \\
\hline$"$ & 2 & 14.7 & 21.1 & 2.20 \\
\hline$"$ & 3 & 8.6 & 10.2 & 1.06 \\
\hline $\operatorname{tcn}$ & 1 & 114.5 & 13.7 & 1.65 \\
\hline$"$ & 2 & 9.5 & 13.9 & 1.68 \\
\hline$"$ & 3 & 8.2 & 11.6 & 1.40 \\
\hline $\operatorname{tnv}$ & 1 & 25.0 & 18.0 & 3.75 \\
\hline " & 2 & 36.4 & 67.1 & 13.99 \\
\hline " & 3 & 20.5 & 19.2 & 4.00 \\
\hline
\end{tabular}




\section{Table IV}

Descriptive Statistics of t-tests on Comparisons of Sex of Non-novel and Novel with Regards to the Sex of the Mouse Being Tested:

\begin{tabular}{|c|c|c|c|c|}
\hline Indep.Var. & Dep.Var. & Mean & $\mathrm{SD}$ & SE of Mean \\
\hline ns1 & nvsx-0 & 2,3 & 2.9 & .53 \\
\hline$"$ & nvsx-1 & 2.5 & 1.7 & .28 \\
\hline$"$ & nnsx-0 & 2.1 & 2.0 & .29 \\
\hline$"$ & nnsx-1 & 2.9 & 3.3 & .22 \\
\hline $\mathrm{ns} 2$ & nvsx-0 & - & - & - \\
\hline$"$ & nvsx-1 & - & - & - \\
\hline$"$ & nnsx-0 & 1.5 & 1.8 & .29 \\
\hline$"$ & nnsx-1 & 2.2 & 2.1 & .16 \\
\hline ns3 & nvsx-0 & 3.9 & 5.0 & .91 \\
\hline$"$ & nvsx-1 & 4.0 & 2.3 & .37 \\
\hline$"$ & nnsx-0 & 2.3 & 2.5 & .72 \\
\hline$"$ & nnsx-1 & 4.3 & 3.8 & .51 \\
\hline $\operatorname{tnn}$ & nvsx-0 & 15.2 & 29.1 & 5.32 \\
\hline$"$ & nvsx-1 & 12.4 & 11.7 & 1.87 \\
\hline$"$ & nnsx-0 & 8.4 & 9.8 & 1.42 \\
\hline$"$ & nnsx-1 & 15.5 & 24.9 & 1.65 \\
\hline $\operatorname{tcn}$ & nvsx-0 & - & - & - \\
\hline$"$ & nvsx-1 & - & - & - \\
\hline " & nnsx-0 & 6.5 & 9.8 & 1.6 \\
\hline$"$ & nnsx-1 & 11.6 & 13.8 & 1.1 \\
\hline
\end{tabular}


Table IV, continued

$\begin{array}{lllll}\text { tnv } & \text { nvsx-0 } & 28.8 & 52.9 & 9.7 \\ " & \text { nvsx-1 } & 26.1 & 30.8 & 4.9 \\ " & \text { nnsx-0 } & 14.5 & 18.9 & 5.5 \\ " & \text { nnsx-1 } & 30.0 & 44.5 & 5.9\end{array}$


Table V

Probabilities, tests, and variables used (95\% significance level).

Probability $(\mathbf{p}<.05)$

Variable $\mathrm{X}^{2} \quad$ Eriedman t-test $\quad$ Mult.Reg.

tnv;odors1-3 19.4***,.0001

tnv;odors $1 \& 3$

$.81, .888$

tnv;odors $1 \& 2$

$-.79, .031$

tnv;ns3;nvsx=1

$.54 *, .027$

tnv;ns3;nvsx=0

$1.09 *, .035$

tnn;odors 1-3 1146,.000 $10.7^{* *}, .0011$

tnn;odors1\&3

$3.11, .000$

tnn;odors $1 \& 2$

$1.19, .203$

tnn;odors $2 \& 3$

$2.51 * *, .001$

tnn;tcn;nnsx =1

$-1.94 *, .026$

tcn;odors1\&3

$2.91 *, .007$

tcn;odors $1 \& 2$

$2.14, .132$

tcn;odors $2 \& 3$

$.58, .378$

tcn;odors 1-3 768,.000

tnn;ten;nnsx $=0$

$-2.10 *, .038$

ns1;ns2

$8.12 * *, .004$

ns1;odors1-3 359,.000

ns1;odors1\&3

$3.05, .000$

ns1;ns2;odors1-3

$8.38 *, .0152$

ns1;odors1\&2

$1.68 * .048$

$*=p=\leq .05 ; * *=p=\leq .01 ; * * *=p=\leq .001$ 
Table V, continued

Variable $\quad x^{2}$

ns1;tr;odors 1-3

Eriedman

t-test

Mult.Reg.

$15.7^{* * *}, .0004$

ns1;ns2;sex

$8.63 *, .0134$

ns1;ns3;odors1-3

$17.4^{* * *}, 0002$

ns2; odors1\&2

$2.78, .092$

ns2;odors1-3 $170, .000$

ns2;tr;odors1-3

$5.89, .0526$

ns2;ten;odor1

$3.77, .006$

ns2;tcn;odor2\&3

$.89, .325$

ns3;odors2\&3

$.21^{*}, 007$

ns3;odors1-3 44.2,.000

$.48, .511$

ns3;odors1\&2

$.07, .137$

ms;tr;odors1-3

$21.4^{* * *}, .0001$

tnn

$3.14^{*}, .0019$

$\operatorname{tnv}$

$2.48^{*}, .0156$

ns1

$2.95 *, .0036$

ns3

$3.09^{*}, .0029$ 


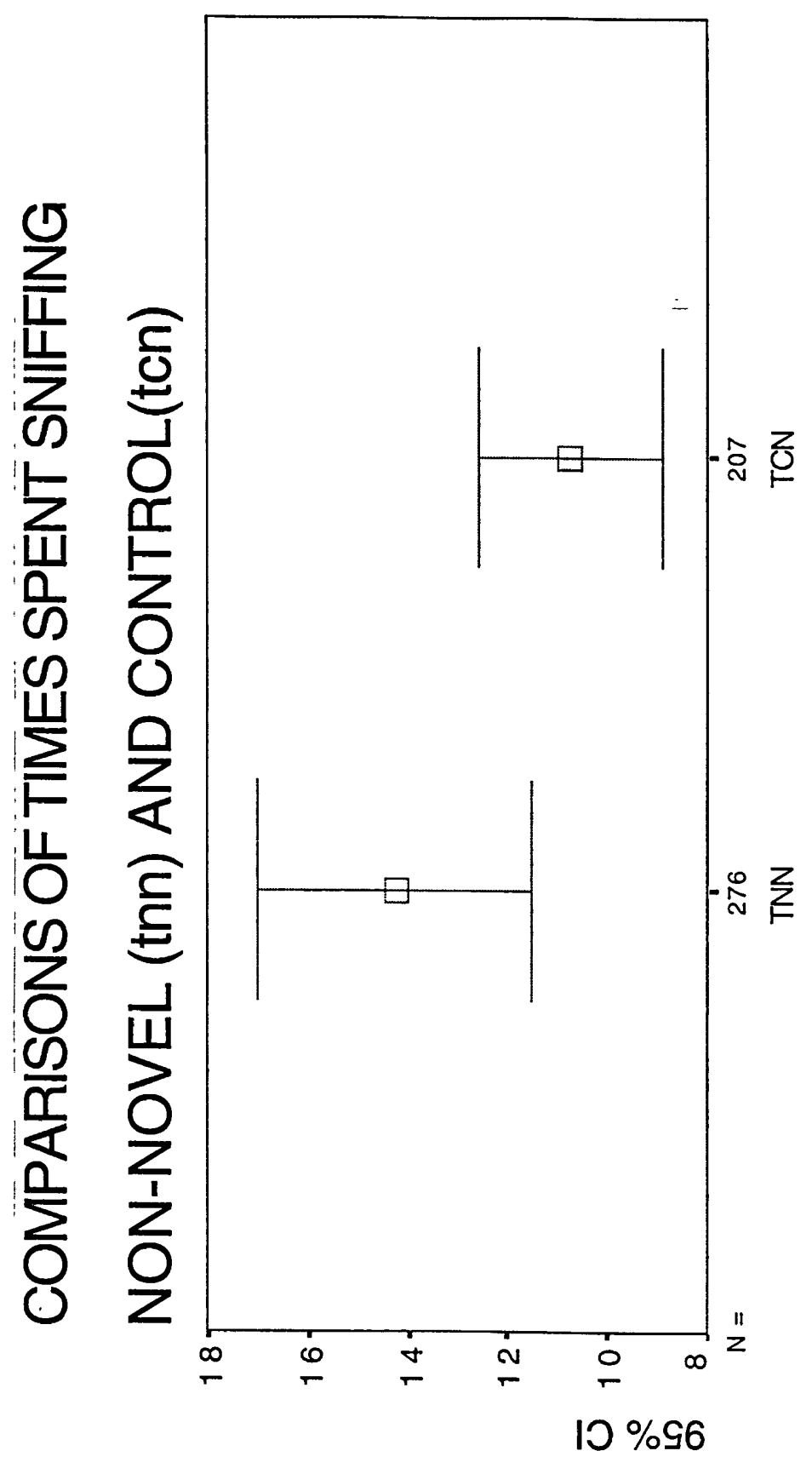




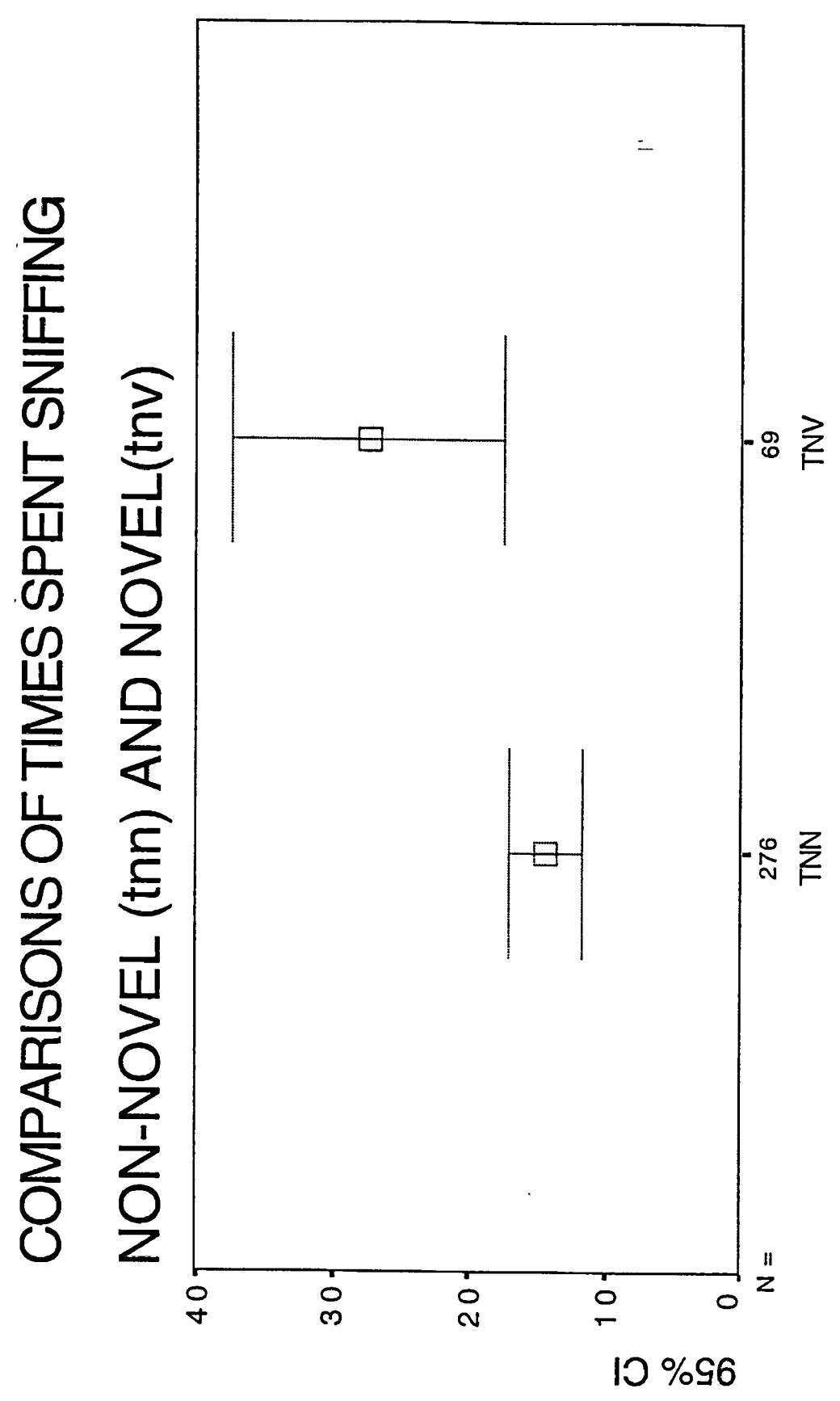




\section{COMPARISONS OF NUMBER OF SNIFFS OF}

NON-NOVEL (ns1) AND CONTROL(ns2)

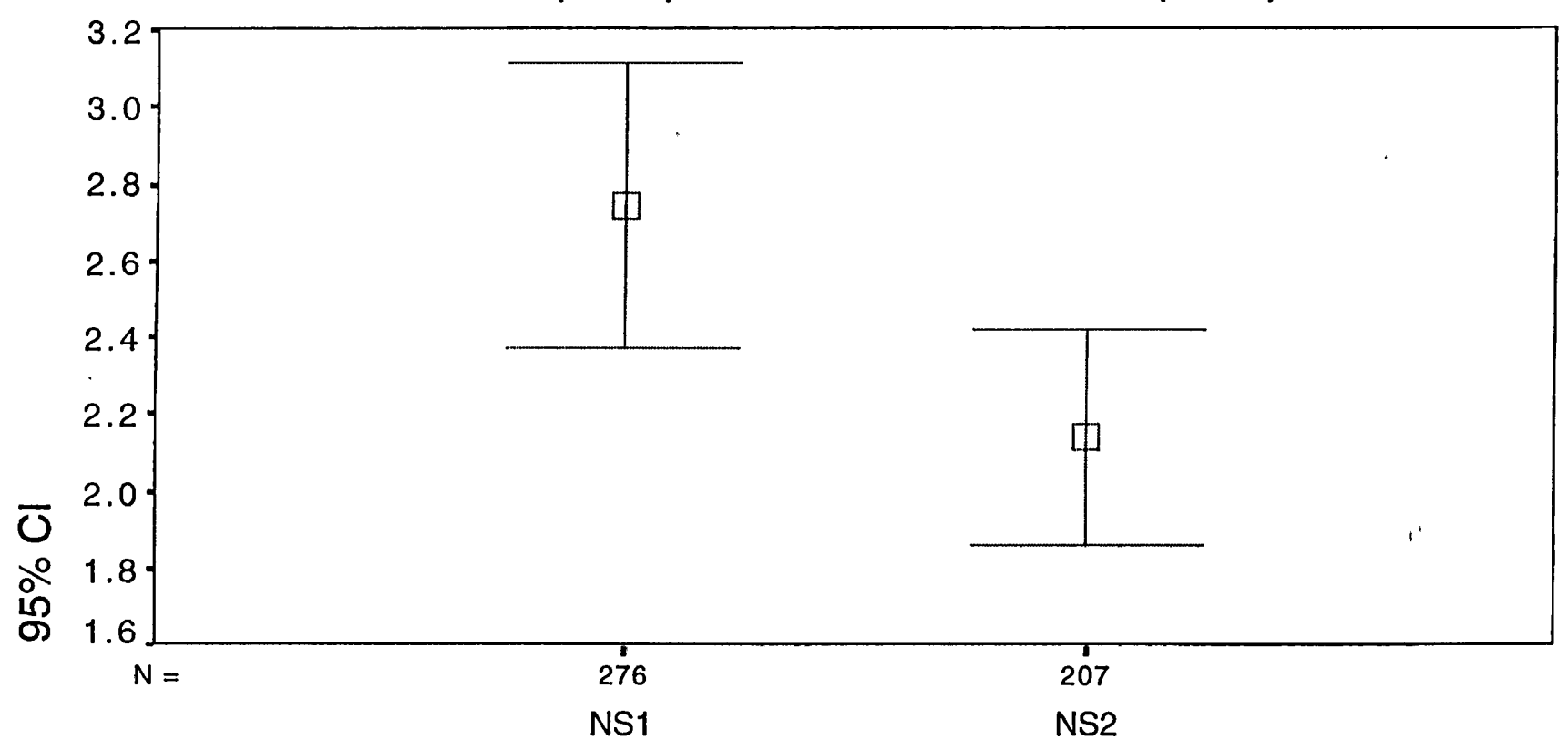




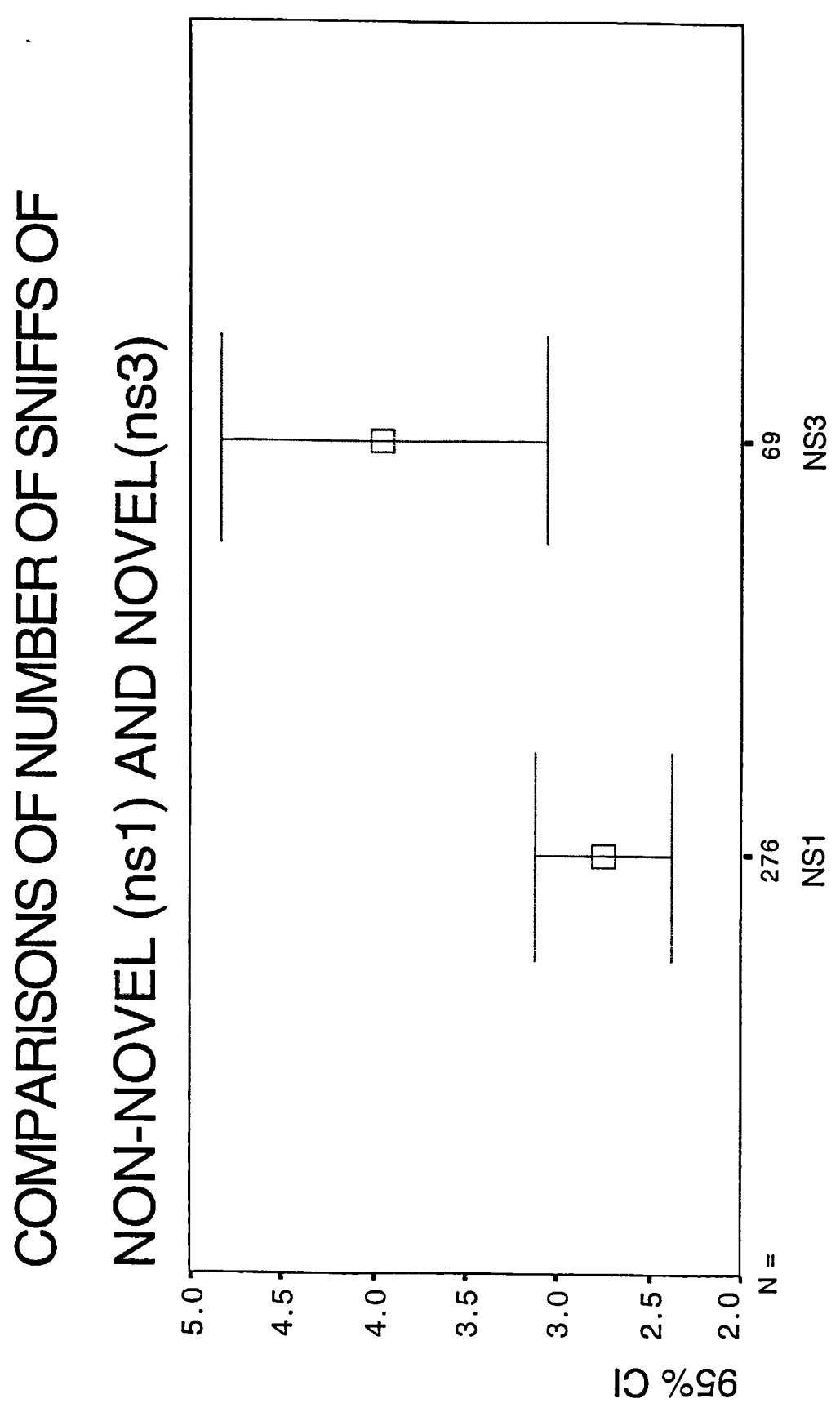




\section{APPENDIX A}

Variables, their definitions, and their abbreviations.

ns1=number of sniffs of non-novel (familiar) odor.

ns2=number of sniffs of control.

ns $3=$ number of sniffs of novel (unfamiliar or foreign) odor.

$\operatorname{tnn}=$ amount of time in seconds spent sniffing the non-novel odor.

ten=amount of time in seconds spent sniffing the control.

tnv=amount of time in seconds spent sniffing the novel.

odor $1=$ anogenital odor.

odor $2=$ harderian gland odor.

odor $3=$ mouth $/$ nose odor.

nnsx- $0=$ sex of non-novel mouse was opposite the sex of the tested mouse.

nnsx-1=sex of non-novel mouse was same as the sex of the tested mouse.

nvsx $-0=\operatorname{sex}$ of novel mouse was opposite the sex of the tested mouse.

nvsx-1=sex of the novel mouse was same as the sex of the tested mouse.

$\operatorname{sex}=\operatorname{sex}$ of the mouse being tested. 